\title{
Research on Brand IP Shaping in the Era of Brand Personification - Taking Disney's Cultural Industry as an Example
}

\author{
Lu Wang ${ }^{1, *}$ Yujia Zhai ${ }^{1}$ \\ ${ }^{1}$ College of Arts and Sciences, Shanghai Polytechnic University, Shanghai 201209, China \\ *Corresponding author. Email:15658908@qq.com
}

\begin{abstract}
This paper studies the brand IP shaping of Disney's cultural industry in the era of personification from the four dimensions of content, channels, methods, and effects, and elaborates how to use IP resources to develop into the successful secret of IP shaping of the global entertainment kingdom brand in the process of Disney's cultural industry IP entire industry chain operation model. At the same time, this paper also analyzes the shortcomings and improvement strategies.
\end{abstract}

Keywords: Brand personification, Disney, Cultural industry.

\section{INTRODUCTION}

As it known to all, it is important to shape brand IP means explore and digging out the inner culture and value of the brand, nourish the brand culture, and absorb the value orientation and identity of consumers as nutrients to increase the stickiness between consumers and the brand. In the current situation where products are becoming more and more homogeneous, people's consumption concepts have gradually shifted from material needs to spiritual enjoyment. When the cultural connotation of a brand is related to the fundamental values or personality characteristics of consumers, it may develop into a "personalized IP".[1] Compared with the external manifestation of the brand, brand IP is more likely to trigger recognition of personality and spirit deep down, and then go beyond the association of the product itself and expand the commercial value of the brand.

*Project: This article is the related research results of the 2021 ideological and political-navigation course "Management" of Shanghai Polytechnic University (JG2020-210).

\section{RESEARCH ON IP SHAPING OF DISNEY'S CULTURAL INDUSTRY}

\subsection{The Shaping Content of Disney's Cultural Industry Brand IP}

\subsubsection{The Core of Brand Culture: Happiness}

"Let everyone laugh from the heart" is what Walt has been doing since the birth of Disney. With the starting point of doing everything possible to create happiness for people, Disney's animated films are to teach through entertainment, allowing people to comprehend the protagonist's spirit and qualities such as honesty, kindness, wit, humor, etc. in the joy and wonderful enjoyment and experience.

Disney strives to guide families and children positively, adding more joyful elements to their lives through a variety of activities, and hopes to inspire people to maintain vigor and vitality in the face of life. In the world of Disney, the cultural connotation of the brand and the spiritual core of IP characters are fully demonstrated. The reason why Disney culture can be marketed all over the world is that it can bring people happiness, confidence, dreams and strength. [2] 


\subsubsection{Brand Positioning: Family Entertainment}

The ultimate appeal of Walt's animation industry is to realize the sharing of happiness. Walt pays more attention to social benefits in the production of animated movies, and pursues the production of healthy, warm and humorous family movies; he focuses on continuously providing stories suitable for the whole family, with fuller emotional expression, and more touching people's hearts.

Disney attaches great importance to family values and has a great relationship with Disney's brand culture that promotes happiness and sharing. The entertainment model provided by Disney can be shared by all generations. Walt's original intention to establish Disneyland was to hope that adults and children can play together, which fully reflects the brand positioning established at the beginning of the Disney brand — family entertainment. Dedicated to the concept of sharing entertainment for families, it can be said to be a beacon that illuminates the road to Disney's success and pave the way for Disney in the future.

\subsection{Shaping Channels of Disney's Cultural Industry Brand IP}

\subsubsection{The Classic Image of the Original IP}

Mickey, who appeared in Disney's first animated cartoon "The Steamboat Willie", set the tone of Mickey's character in his reckless, simple and innocent image. Mickey's funny actions and optimistic and cheerful personality subtly comforted the hearts of the American people, which was shrouded in the gloom of the Great Recession of 1929-1933, and thus gained people's love. As a result, Mickey with two round ears, a pear-shaped body, a pair of white gloves, red shorts and yellow shoes became Disney's first high-quality personalized image IP.

The IP image created by Disney adjusts the character image according to changes in the times, environment, and historical background. For example, Mickey was initially a mischievous and always troublesome hapless man, but with the development of the times, Mickey began to serve the society, became brave, practical and contagious, strongly responded to Roosevelt's New Deal, making the American people regain full confidence. The breakthrough of the character image gives people the courage to break the rules and shackles, encourages people to pursue themselves, and is sought after by a broad audience.

\subsubsection{The IP Character of Adapting and Excavating}

Disney's first step was produced in 1937 and adapted from "Snow White and the Seven Dwarfs" from "Grimm's Fairy Tales". Some scholars, represented by the famous American folklore expert, Dr. Jack Gippes, think that this film is a model of adaptation of children's literature, especially the seven cute dwarfs with comic characters, which are humorous. The humorous and optimistic atmosphere infects the audience and adds a comedy color to the movie. The small animals in the movie are also personified ${ }^{1}$. They are kind, simple, lively and lovely, enrich the emotional color of the original work, and are a positive innovation and adaptation.

Disney excavates excellent works from all over the world into the blueprint of the story of animated films, combining the background of the time, as well as the understanding of social habits and cultural cognition, and then integrates its own thinking to innovate and surpass, thus forming its own unique story style. These modified and adapted works are radiated with new vitality. They can be preserved and even passed on in modern society through new media methods. They once again flood into people's vision through secondary communication, and contribute to their animation kingdom in the continuation of the original IP.

\subsubsection{Mergers and Acquisitions $(M \& A)$ Leapfrog IP Development}

If originality and adaptation are regarded as the capable assistant of Disney's cultural industry development escort, then M\&A are the backbone of Disney's leapfrog development. Mergers and acquisitions enable Disney to break through from the unknown in Hollywood, strengthen the power of the IP family, and create a new development direction for the planning of the territory, which has made this great achievement today. Each merger and acquisition complements each stage of Disney's development. Disney's brand value and content competitiveness have been further enriched and improved, which in turn helps Disney continue to perform its dominance. The M\&A history with

1. Bao Yuheng, Zhong Dafeng, Research and Criticism of "Disney" by American Scholars (Section 2) [J]. Movie Review, 2009(09):1-5. 
historical significance of Disney can be roughly summarized as follows: ("Table 1")

Table 1. Disney M\&A initiatives (partial)

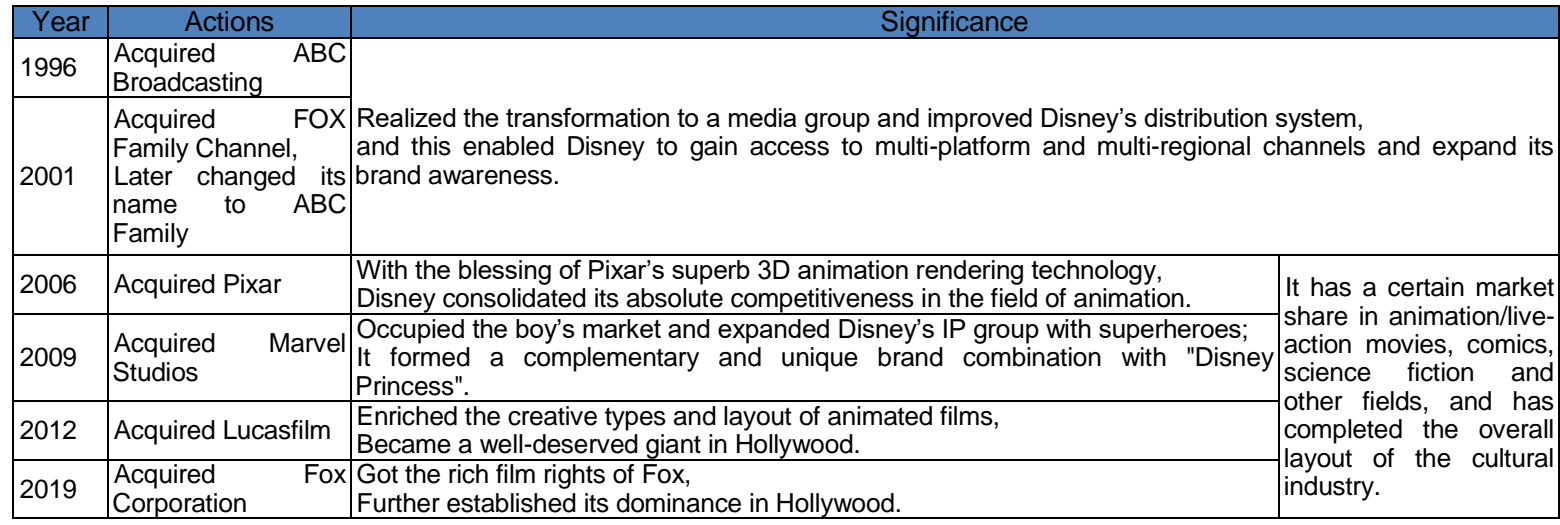

\subsection{The Methods of Shaping Disney's Cultural Industry Brand IP}

\subsubsection{IP Cultivation - Vertical Segmentation Strategy}

While exploring new development directions, Disney has made small but specialized subdivisions in content. Among them, most of the reason why there are a large number of loyal fans in each segment is to fully consider the matching degree of the IP image and the target market, which is very similar to the principle of "things are gathered together by groups, and people are divided by groups". Under the influence of the "interaction force" between consumers and brands, if the personification of the brand IP matches the consumer's self-pursuing vision to a high degree, consumers will unconsciously develop a sense of identity with the brand, and increase their choice and loyalty to the brand. [3] Thanks to the content segmentation, from the vertical drive of the film and television field to music, games, theme parks and derivative products, a strong and complete IP industry chain has been developed. Original animation, as the key to this strategy, is to leverage the fulcrum of the entire "Disney Kingdom", and the follow-up needs to establish a product line, continue to produce IP derivative products, and finally build commercial multi-scenario penetration capabilities.

\subsubsection{Realization of IP-Recurrence of the Spiritual Core}

\subsubsection{Disneyland}

Disney has established theme parks, relying on the integration of IP image and urban humanities, with the positioning of "industry + culture + tourism + commerce". Disney has constructed a characteristic themed entertainment complex. The significance of the reappearance of the Disneyland scene is to act as an energy field full of happiness and magic. Consumers can relive good memories with family and friends and create new happy memories in the experience activities full of ritual feelings. Its accurate grasp of the audience's psychology is a bonus item for successful Disneyland's realization of IP monetization.

\subsubsection{Derivative Products}

IP derivative products are another main field of fan consumption under the powerful effect of IP sources, bringing very considerable traffic and profits; providing consumers with a way of life and emotional expression that can be implanted in emotional sustenance. The directional consumption that has been precipitated over a long period of time has the potential to create immeasurable economic benefits and has directional enlightenment for IP planning. In recent years, Disney has also actively launched cross-industry cooperation in various aspects of clothing, food, housing and transportation, demonstrating the brand's diverse personality charm and strong plasticity, giving the brand an opportunity to break through restrictions. 


\subsection{The Shaping Effect of Disney's Cultural Industry Brand IP}

\subsubsection{Brand Effect}

Disney's IP operation is based on a thorough analysis of the culture of the times, to grasp the yearning and emotional pursuits in people's hearts, and to provide positive values. The children of the first generation accompanied by Disney's firstgeneration IP such as Mickey and Donald Duck have already reached old age. From a brand perspective, the brand effect is integrated into people's memory, and memory will subtly affect people's habits. The Disney brand has integrated into the times through popular IPs, and continuously conveys happiness and hope to people. The essence is through cultural effects, the purpose of probating people to improve the relationship between people and between people and brands, and it has also become a brand memory that can overlap in the growth process of generations, and a cultural memory passed on from generation to generation.

\subsubsection{Brand Value}

With the deepening and stability of the relationship between Disney and consumers, the value of brand equity increases in proportion to consumers' emotional investment in the brand. The brand equity extracted by David Ike is mainly reflected in the following five aspects: The first is brand awareness. [4] Disney's "big name" is sufficiently representative in American culture. The second is brand recognition. For the third consecutive year, Disney has ranked fourth in the list of the world's most admired companies. The third is brand associations, such as well-made animated films, Disneyland or Disney's super IP group. The fourth is brand loyalty, which is mainly reflected in the $60-70 \%{ }^{2}$ average revisit rate of Disneyland. The fifth is other assets, including the design, construction, production and other patents of Disneyland, trademarks applied for animation images, animation works, IP images, audiovisual products, book copyrights, etc. involved in the vertical segmentation field. [5]

Brand value is integrated and quantified from the above five abstract indicators. It is the most intuitive indicator to measure brand equity. About Disney's brand value and growth in the past ten

2. Data source: "2013-2017 China Theme Park Market Investment Analysis and Prospect Forecast Report". years, as well as its global ranking are as follows: ("Table 2")

Table 2. Disney Value

\begin{tabular}{|l|l|l|l|}
\hline Year & Brand value $(\$ \mathrm{~m})$ & Ranking & Increment \\
\hline 2010 & 28,731 & 9 & $+1 \%$ \\
\hline 2011 & 29,018 & 9 & $+1 \%$ \\
\hline 2012 & 27,438 & 13 & $-5 \%$ \\
\hline 2013 & 28,147 & 14 & $+3 \%$ \\
\hline 2014 & 32,223 & 13 & $+14 \%$ \\
\hline 2015 & 36,514 & 13 & $+13 \%$ \\
\hline 2016 & 38,790 & 13 & $+6 \%$ \\
\hline 2017 & 40,772 & 14 & $+5 \%$ \\
\hline 2018 & 39,874 & 14 & $-2 \%$ \\
\hline 2019 & 44,452 & 10 & $+11 \%$ \\
\hline 2020 & 40,773 & 10 & $-8 \%$ \\
\hline
\end{tabular}

From the above data, it can be seen that Disney's brand value has continued to rise from 2012 to 2017. It increased by $14 \%$ in 2014 and reached its peak in the past ten years in 2019 , and it has risen to the fourth place in 2020. Affected by the general environment, the growth volume has declined, but the ranking still maintains the tenth place. Disney's prudent brand personification shaping strategy, rightfully leads the world in the entertainment media industry, and can gain a firm foothold in various rankings.

\section{PROBLEMS IN THE IP SHAPING OF DISNEY'S CULTURAL INDUSTRY}

\subsection{Content Dimension: Modelized Output}

As a representative of popular culture, Disney inevitably took a detour in film and television production, blindly pursuing the accumulation of quantity and outputting a series of sequels. Stereotyped characters, stylized plots, and graphical visual effects, the adventure story matched by the "three-piece" can only be said to be a pseudopersonalized product, and even gradually lose the original artistic originality, and there are faults that are difficult to detect. Although it seems that Disney's works are prolific, and the characters of the IP family are gradually growing, over time this kind content of the story, that the protagonist encounters difficulties, experiences setbacks, is

3. Data source: Interbrand - Disney Value https://interbrand.com/best-global-brands/disney/ 
inspired and inspired by accident, completes a gorgeous reversal, realizes self-worth, overcomes difficulties or fights wits and courage with the villain and finally wins, cannot bring freshness and shock to the audience. In most cases, the end of the story can be guessed more than halfway through the plot. Over time, the audience develops aesthetic fatigue, which directly affects the Disney market into a downturn.

\subsection{Channel Dimension: The Invasion of American Values}

In the initial stage of Disney animated films, most of the works were products of Western cultural background, and the main purpose of the story was to convey a direction that was in line with the current aesthetics. Limited by its own historical and cultural resources, animated films adapted by Disney have been penetrated by strong American culture, using "Americanized" global materials to create "American taste", promote the "American spirit", and sell American ideology. Disney is just learning from, or just embezzling a shell, in order to cater to the trend of the times and the strategy adopted. Disney injected the characters they understood and what they believed to be real materials. Such an IP exuding American spirit and national beliefs was born, and it also achieved Disney's goal of exporting American culture, lifestyle and mainstream values to the world. When individualism, liberalism, and the American dream become the main theme of a film, people will slowly and inadvertently accept the American values hidden in it, and even more will surrender to the American hegemony system.

\subsection{Method Dimension: Excessive Pursuit of Commercial Interests}

In "L'assassinat de Mickey Mouse", Pierre Pigott mentioned that Disney was completely free to polish Mickey's image to perfection between 1930 and 1940, turning him into an empty shell that actually made money for himself. In this cold process, people saw Mickey being emptied of fresh nourishment, and saw that he was ultimately just a stiff, hollow but intriguing smile on the advertising balloon. ${ }^{4}$ This point also applies to the derivative products that will be rolled out in the Disney industry chain in the future: when Mickey's series

4. Tang Ming, "Thousand Rats in One Style": The Capital Logic Behind the Changes of Animation Images [N]. WHB, 2014-11-10 (T05). of merchandise floods all aspects of our lives, it seems to be a complete success, but it is actually an excessive pursuit of commercial interests that leads to a continuous decline in brand value. In other words, every consumption of a cultural product related to Mickey Mouse will bring about a diminishing marginal utility of the next cultural product related to Mickey Mouse, so that the growth rate of total utility will continue to slow down and eventually tend to hardly increase.

\subsection{Effectiveness Dimension: Barriers in Cross-cultural Communication}

Disneyland's first overseas exploration in Tokyo, Japan was a great success. On the other hand, Disneyland in Paris did not meet the expected profit but suffered a serious loss for more than 20 years. [6]It can be described as a strong barrier to Disney's cross-cultural communication. From a historical and cultural perspective, the park used English as the official language at that time, but it was rejected by the staff and tourists. In addition, the catering service and food supply are not satisfactory, and no alcoholic drinks are provided in the park. From the perspective of economic development, the completion and opening hours of Disneyland Paris coincided with the severe economic recession in Europe. The economic downturn directly affected the number of visitors to Disneyland, whether in shops, restaurants or hotels, and their buying behavior. This series of cascading effects directly smashed the "dream" of the United States that wants to quickly recoup its costs by relying on monopolistic high pricing. In the offseason, the flexible system adopted for personnel management fundamentally conflicted with the French regulations on inflexible labor. The superposition of piles and pieces of cases caused strong dissatisfaction among the French people. [7]

\section{COUNTERMEASURES FOR IP SHAPING OF DISNEY'S CULTURAL INDUSTRY}

\subsection{Content Dimension: Changes in Creative Mode and Story Performance}

In recent years, the transformation of the "serialization" mode of Disney's adventure stories is mainly reflected in the realization of variations in the story plot and story structure, and the story expression methods have become increasingly 
mature and diversified. Taking "Coco" as an example: Judging from the storyline, the film contains a lot of Mexican elements such as the protagonist of the Dia de Muertos (Day of the Dead), the Aztec chrysanthemum, and the patron saint "Eborigi". These make people further appreciate Mexican culture as the plot pushes forward, especially Mexicans pin their thoughts on the dead on the annual "Dia de Muertos". From the perspective of the structure of the story, "Coco" adopts a field narrative - Miguel went from the world to the world of the undead, experienced a twists and turns of adventure and then returned to the world. It is a story about personal growth and reconciliation with family members, breaking through numerous obstacles to uncover the truth, but also a story about persisting in dreams and feeling family affection in memories. [8]

\subsection{Channel Dimension: Breakthroughs in Universal Value Packaging and Adaptation Models}

In the experience of Disney animation IP characters, it reflects the universal elements contained in the story, conveys its core values to the audience, and strives to be recognized. [9] Although the materials of the stories from different countries in the world are different, the theme and emotions expressed are not the same, but they all contain universal themes, which have become a necessary condition for Disney animation films to be favored and from the United States to the world. The early Disney adaptations of literary works were basically based on the principle of respecting the original works, but with Disney's keen awareness and innovative ability to change the times, the adaptation model also constantly seeks different explorations and breakthroughs from the past. After the material conversion, the new perspective of the story is activated and disseminated in line with the concept of the times, and in a way that is more acceptable now, it gives the audience the charm of traditional literary works, and has a new opportunity to interpret in the process of reviewing it.

\subsection{Method Dimension: Protection of Consumer Quality}

Out of the emphasis on the quality of consumer products sold in directly-operated stores, Disney's Consumer Products Department adheres to the principle of "less but refined" and has slowed down the opening of directly-operated stores. In the selection and management of licensees, Disney not only requires licensees to have more than 5 years of industry experience and relevant qualifications in the manufacturing, distribution or retail of related professional products, but also formulates the "The Walt Disney Company - Manufacturer Code of Conduct" in its production work, and translated it into 50 major world languages, requiring all manufacturers with Disney-authorized product production business need to strictly abide by this code, and should accept and actively cooperate with Disney's irregular inspection and supervision to ensure the quality of the products provided to the public. [10]

\subsection{Effectiveness Dimension: Integration of Globalization and Localization}

Although Disney has experienced painful lessons in its overseas expansion, it has been learned that the integration of globalization and localization is the magic weapon to make the culture of Disneyland and the host country coexist in harmony and promote the long-term development of each other. After absorbing the experience of Disneyland Paris, the planning and design of Shanghai Disneyland has done a lot of homework in the study and research of traditional Chinese elements and popular culture in order to respect and transplant local culture. First, it is reflected in the visual environment. The design of the fantasy fairy tale castle incorporates famous Chinese flowers such as peonies and traditional elements auspicious clouds as embellishments, taking into account decoration and the creation of a sense of belonging; Disney Town has inherited the Shanghai style Shikumen style as a whole Second, it is reflected in themed performances. The world's first Chinese version of the musical "The Lion King" was performed at the Walt Disney Theater in Disney Town. It was grafted with Chinese pop music and interspersed with puppet shows, shadow puppet shows and Beijing accents that are rich in traditional Chinese national characteristics.

\section{CONCLUSION}

After more than 90 years of development and exploration, Disney has achieved the maximum value of the IP commercialization road through a group of powerful IP groups such as the original Mickey, the Disney princess adapted from the Disney princess, and the superhero acquired by mergers and acquisitions. It makes the IP ecosystem prosperous and stable, completes the 
brand IP upgrade with an absolute leading advantage, and accumulates brand strength and value in the cultural industry. It can be said to have epoch-making significance, and provides rich material for the research of brand IP shaping, and also provides a feasible idea for other brand building and cultural industry development.

\section{AUTHOR'S CONTRIBUTIONS}

Lu Wang wrote and revised the paper, and Yujia Zhai compiled and proofread the paper.

\section{REFERENCES}

[1] Shi Yahui, The Value and Strategy Research of Brand Personification Under New Media Environmet [D]. Communication University of Zhejiang, 2018. (in Chinese)

[2] Song Chuqiao, The Practice and Exploration of Disney Entertainment Industry from the Perspective of IP [D]. Hunan Normal University, 2019. (in Chinese)

[3] Zeng Miao, Brand IP Shaping Strategy and Innovation Under the Trend of Smart Media - Taking Wang Zai IP as an Example [J]. New Media Research [J]. New Media Research, 2020, 6(19): 45-48. (in Chinese)

[4] Zhang Yu, Research on Brand Management of Disney Company [D]. Heilongjiang University, 2015. (in Chinese)

[5] Chen Si, Application of IP-based Brand in the Era of "Internet plus" [J]. Journal of Wuyi University, 2020, 39(08): 33-38. (in Chinese)

[6] Jing Xi, Talking about "Disney" Culture [J]. Market Modernization, 2008(26): 308-310. (in Chinese)

[7] (France) Pierre Pigott, L'assassinat de Mickey Mouse [M]. Wang Mingrui, trans. Shanghai: Shanghai People's Publishing House, 2014. (in Chinese)

[8] Bao Yuheng, Zhong Dafeng, Research and Criticism of "Disney" by American Scholars [J]. Movie Review, 2009(08):5-7. 2009(09):15. (in Chinese)

[9] Xie Jinghui, Enlightenment of Disney's Brand Effect [N]. WHB, 2016-06-16(005). (in Chinese)
[10] Cheng Weijia, Disney's Marketing Strategy Based on the IP Industry Chain [J]. Communication and Copyright, 2017(12): 131-132. (in Chinese) 